\section{HOSPITAL NOTES.}

BY E. SYMES THOMPSON, M.D.,

Assistant-Physician to the Hospital for Consumption and Diseases of the Chest, Brompton.

IT is often difficult to give steel in private practice, or to the well-fed in-patients at our hospitals. With out-patients, however, it rarely disagrees, and may be given in phthisis even when special remedies are also required to check cough, hæmoptysis, diarrhœa, or other complications.

Two years ago, the plan of tabulating the results of treatment suggested in Dr. J. Jones's book on Iron in Phthisis was adopted; and many hundred cases were thus classified under the heads-1, Mach Improved; 2, Improved; and 3, Not Improved. In the accompanying table, these three heads have been reduced to two, as the danger of error in deciding whether a person is "improved" or "not improved" is much less than in estimating whether the case should be entered as "much improved" or "improved".

The first line (I) in the table represents the percentage observed under the use of the following medicine, administered every four hours.

B Liquor. ferri perchloridi, spirit. ætheris chlorici, àà miiss ; infusi quassiæ 3 ij. M.

The second line (II) represents the percentages under the similar use of a mixture of chloric ether (miiss) and infusion of quassia ( $3 \mathrm{ij}$ ) - the iron being omitted.

The third line (III) shows the result of the following medicine-the iron being replaced by nitromuriatic acid.

Bo Acidi nitro-muriatici dil. mviiss; spir. æther. chlor. miiss ; infusi quassiæ 3 ij.

The fourth line gives the percentage under the use of the following-sal volatile being substituted for the iron.

R Spirit. ammon. aromat. Mx $x$; spirit. æther. chlor. Miiss ; infusi quassiæ $3 \mathbf{i j}$.

In all cases, the medicine was given at intervals of four hours.

\begin{tabular}{rrrrr}
\multicolumn{5}{c}{ Table of Percentages. } \\
No. & & & Improved. & Not Improved. \\
I. & - & - & 84.26 & 15.74 \\
II. & - & - & 73.39 & 26.61 \\
III. & - & - & 76.97 & 23.03 \\
IV. & - & - & 77.65 & 22.35
\end{tabular}

From this, it will be seen that steel proved useful in a larger proportion of cases than the other remedies employed. It may be mentioned that the liquor ferri perchloridi (British Pharmacopcia) miiss are equal to seven minims of the tincture of sesquichloride of iron.

I have during the last ten years prescribed steel in more than 15,000 cases, and have found the perchloride or sesquichloride the most universally applicable form. When given with a little chloric ether and a bitter, it is not more apt to disagree than the nitrate, citrate, or acetate. The reduced iron may, like steel wine, be given almost with impunity in every case; but its chalybeate effect is so doubtful, and so inferior to the perchloride, that it cannot be mentioned with it.

The following brief notes, taken in the out-patient room at the Brompton Hospital, may be given in illustration of the remedial value of iron. More may often be learned from two or three plainly recorded cases than from sheets of statistics.

CAst I. Case of Tolerated Cavity in both Lungs.
H. S., aged 27, groom, when first seen in December 1863, had suffered from cough four years, with purulent expectoration. $\mathrm{He}$ had hæmoptysis, nightsweats, and loss of flesh. The respiration was bronchial, with hurried crepitation; gurgling and pectoriloquy were heard under both clavicles, but more extensively on the right than on the left side.

This patient remained almost constantly under treatment till July 1866, requiring frequently remedies directed to check gastric irritability-e.g., bismuth, hydrocyanic acid, ammonia in effervescence, etc.; but taking continuously cod-liver oil and iron.

The patient is now able to work; but applied on February 1st, 1867, with a bronchial attack affecting the whole of the left lung. The physical signs are now, cavernous respiration on the right side, and pectoriloquy above the clavicle and above the scapula; on the left side, flattening, very marked dulness with cracked-pot sound, amphoric resonance and pectoriloquy over the upper third, and sibilant and crepitant rhonchi to the base.

This is a fair example of the ordinary form of tolerated cavity; but it is not usual to find a man capable of much daily work when both lungs are thus affected.

CASE II. Tolerated Cavity. R. P., aged 23, when first seen in May 1863, gave this history. His mother's family was phthisical. His illness commenced three years ago, after ague, with slight cough and scanty expectoration, pain after food, and sickness on coughing. On the right side, respiration was puerile throughout; at the left apex were dulness, cracked-pot sound, and moist gurgling rhonchus.

In May 1866, slight increase of weight occurred under the use of cod-liver oil with iron and chlorate of potash, and occasional small blisters beneath the collar-bone. The expectoration and night-sweating ceased. The appetite was good; and the physical signs noted were, in the left subclavian region, harsh breathing without moist sound, and tubular breathing with large hurried crackle above the clavicle. The cough increased during the winter. No alteration of weight has, however, occurred; and the progress made in the summer of 1866 seems continuous. Some falling in on the side and contraction of the excavated lung has occurred; but there is still evidence of a considerable vomica in the upper part of the left lung, and it seems improbable that it will ever be entirely obliterated.

It is usual, in cases of tolerated cavity, to find (as in Case III) the excavation limited to one part of the lung, the remainder of which is free, or almost free, from disease. In the cases just detailed, this could not be said to be the case, however; for the physical signs indicated an altered state of pulmonary tissue in the lower as well as in the upper portion

Case 1Ir. Tolerated Cavity, with Profuse Hcemoptysis. C. H., aged 44, coachman, applied as an outpatient in August 1864. His illness began with cough following catarrh, seven months before. Hæmoptysis was profuse - two quarts in the previous night. The cough was violent. His appearance was blanched; the extremities were cold and blue; wasting was considerable. The right side of the chest was dull on percussion, with loud cracked-pot sound, pectoriloquy, and cavernous gurgling.

Cod-liver oil and iron had been taken continuously for two and a half years, with an occasional saline aperient when the hæmoptysis was persistent, and oxide of turpentine lotion to check perspiration. During three years the patient believes that he has coughed up, altogether, at least two pailfuls of blood. Not unfrequently he has nearly filled an ordinary washhand-basin during the night. 
February 1867. For the last six months there has been no return of blood-spitting. The patient has a natural colour, is up ta a day's work, and anxious for a situation. The physical signs of the chest are now, flattening beneath the right collar-bone, with diminighed movement, amphoric breathing, and pectorilogy. There is no gurgling or moist sound. Respuration is normal below the fourth rib and on the left side. The cavity appears to be quite dry. There is but little cough, and no expectoration. The patient is nearly of his natural weight.

CASE IV. The details of this case are more curious than the last, as showing how a patient may continue for years in apparent health with one lung disorganised.

M. M, of Ware, aged 46 , an excise-officer, when aged 16 had cough, loss of flesh, purulent expectaration, hamoptysis, etc. He was told by an eminent physician that the right lung was diseased, and that he could not live six months. Ever since this time he had occasional cough and "shaxp bouts" of bloodspitting ("a chamber-pot, three pailfuls-two or three pints-in half an hour"), but has not lost much flesh in consequence. For several years he expectorated daily an ounce or two of thick drab-coloured phlegm. (The blood had a saltish taste, "like an old copper halfpenny".) In April 1856, when under the care of the late Dr. Theophilus Thompson, he had extensive disease of the right lung; and in October 1866, the physical signs of the chest were the following. There was dulness all over the right side, bronchial breathing below the scapula with large crepitation, oavernous cough, and click; gurgling at the base.

In December last, the sounds of the chest remained the same; but the cough, which, after sleeping in damp sheets, had become more troublesome for a few weeks, was less frequent, and the expectoration no longer frothy. His weight was.11 stone 11 lbs-the same for several years. Pulse 80. Rospiration was hurried only on severe exertion. He can go through a hard day's work without fatigue.

Cuse v. Phthisis : Second Stage. Recovery. D. D., aged 24, draper, was first seen in February 1865 . For sixteen months he had had cough, with yellow expectoration and streaky hemoptysis, and loss of weight (a stone during the last six months). His fither and brother were consumptive.

His digestion was very feeble. The tongue was coated; appetite poor; pupils dilated; feet codematous. Pulse 100 and upwards. The respiration on the right side was rough. On the left side, there was dulness, with crackle; no vesicular murmur. Humied orepitation was heard on coughing, with metallic gurgling above the scapula.

This pationt was carefully dieted. Cod-liver oil was discontinued, as preventing digestion of other food, Nitro-muriatic acid, with chloric ether and a bitter, was given before meals; and an occasional aperient. Oxide of zinc was given for the sweating; and sweet oil with raspberry vinegar for the cough.

In August (six months later), he had an attack of shaxp pain in the right axilla, with loud dry friction. sound beneath the nipple and beside the seapula and on the left side. Hurried crepitation was now to be heard beneath the collar-bone; here the percussionmote was dull, and the vesicular murmur absent Warm linseesd-poultices and spongio-piline, applied to the right chest, gave much relief. Iron was prescribed. In January 1866, he had a sharp attack of homoptysis, which seemed to relieve the sense of weight and oppression in the chest; and the cough became less frequent. But after awhile it became very hard, loud, and tearing. His breath was short. The pupils were still dilated. Ho was easily ex hausted. Pulse 100; appotite poor. In Februaxy
1866, the left side was dullish; wavy and prolonged expiratory murmur was heard above the scapula. In the subscapular region, there was bronohial breathing and cough ; and crepitation on deep inspiration, with light rules to the barse. The chost was painted with croton-oil with benefit; and the cough was relieved with prussic acid linctus.

March. The cough was less hard; the expectoration more easy; the breath less short. Perspiration was checked by oxide of zinc. He wanted to insure his life, but was advised not to attempt it.

September. He had gained four pounds in weight, and looked hearty. Pulse 86. He coughed rarely. On the right side, respiration was puerile; the left was dullish all over. Bronchophony was heard abovo the scapula. The respirrtion in the arilla and beneath the scapula was harsh:

In November, he was examined for insurance by two eminent physicians, and passed with but a slightly increased invalid preminm. The patient has: since married, and retains fair health.

CASE vI. Phthisis : Second Stage: Improvement under Permanent Blister. J. B., aged 42, was first seen in August 1866. He had always been weakly. His father and only brother were phthisical. He had had cough three years, dyspncea on exertion, varied sputa, occasional slight hæmoptysis, profuse night-sweats. He was a thin, haggard looking man, with flushed cheek and restless eye, and a weak compressible pulse. He was much emaciated. On the left side of the chest, the upper third was dull on percussion, with bronchial breatihing; bronchophony, loudly conducted cardiac sounds, and crepitation.

The treatment consisted of coid-liver oil and perchloride of iron, with chloride ether and quassia. A blister was applied beneath the left clavicle, and dressed with savin ointment. Oxide of zinc pills were given at bed-time. The night perspiration soon yielded to the pills, which were then discontinued; but the other treatment has been uninterruptedly persevered in.

February 1867. The patient is now strong and able to work; his complexion and appearance are natural and cheery; pulse steady, 84 in the minute. He coughs very rarely. He has gained much flesh; and the only abnormal sound of the chest now to be detected, is slight dulness on percussion beneath the left clavicle, with prolonged expiratory murmur.

In this case, the good effect of the permanent blister, kept open for six months and not yet closed, has been most marked:

CASE vir. G. B., aged 25, a watchmaker, first applied as an out-patient at the Brompton Hospital in 1860. His mother was phthisical. The patient had suffered for six months from cough, with expectoration and emaciation. The chest-sounds noted were, on the left side, dulness and conducted cardiac sounds. The right side was normal.

In 1865, the left side was dull and flat, with hurried crackle and crepitation at the apex. On the right, there was puerile breathing. Cod-liver oil and iron were prescribed. He spent the winter of 1865-66 Madeira. He amused himself with taking photographs; and; being a musician, did his best to entertain the other patients sent from the hospital, who sat moping for hours. He improved greatly at Madeira; but suffered from diarrhooa on the homeward voyage. $\mathrm{He}$ was very weak on landing, and the benefit gained was then less apparent than real. The chest-sounds are now : under the left claviele, marked fluttering, depression, and diminished movement. Respiration is bronchial. The patient now works hard as a gunmaker

Cases like this are, howevex, so common, that we neust not attach too much importance to the in- 
fluence of the Madeira climate. In these two concluding cases, for instance, the benefit has been as striking though the state of the lung is less satisfactory.

CAsE vrir. E. S., aged 31, widow; dressmaker, had had a cough for three years and night-sweats. In August 1865, on the right ride there were cavernous gurgling; crepitation and prolonged expiration. On the left side, expiration was harsh and prolonged. Cod-liver oil, quinine, and iron were preseribed; and gallic acid to check hæmoptysis. The patient lived near Paris. The physical signs are now, dulness on the right side, with cracked-pot sound; dry cavernous respiration over the upper half of the chest. The left side is normal. She is now able to work.

CA8E Ix. G. J., aged 25, a barman, in September 1865, had a cough, profuse hæmoptysis; night.sweats, and emaciation. The right side was dall; with cracked-pot sound, humid crepitation, and rhonchus to the base. On the left side were rhonchi and sibilus. Cod-liver oil, iron, and zinc pills, were prescribed.

February 1867. The right side is flat and dull, and there are bronchial breathing and bronchophony. The patient has returned to his occupation.

\section{CASE OF}

\section{PARALYSIS OF THE DIAPHRAGM: WITH REMARKS.}

BY P. VICTOR BAZIRE, M.D.LOND. \& PARIS, Assistant-Physieian to the National Hospital for the Paral ysed and Epileptic.

Ir is, I believe, the general impression among medical men, that paralysis of the diaphragm is an immediately fatal affection, and cannot be seen clinically. Between seven and eight years ago; how. ever, I happened to see at the Charité Hospital in Paris, a well-marked example of this affection in an hysterical young woman, who was under Dr. Briquet's care, and $I$ then learnt how to recognise and treat it. Dr. Duchenne, (of Boulogne) who has done so much for neuropathology, a few years before that time, had been the first to show that the diaphragm, although the chief inspiratory muscle, might act imperfectly or not at all, might be more or less paralysed in fact, without instant death or even fatel consequences following, so long as the patient remained tree from any pulmonary complication.

The mistaken opinion which is current in the pro. fession, has, I imagine, arisen from the circumstance that immediate death follows an injury to the spinal cord, sufficiently high in the neck as to be above the origin of the third and fourth cervical nerves, from which the phrenic nerve is mainly derived. The important fact has been overlooked that, in sach cases, all the muscles concerned in the great function of respiration are simultaneously deprived of power; that the intercostal muscles are paralysed together with the auxiliary muscles of respiration, and that hence arise the asphyxia and the rapid death. When the diaphragm alone is affected, tranquil respiration may be carried on seemingly with little trouble; and it is not until the patient taxes his breathing powers to a greater degree than usual by fast walking, running, or exertion of any kind; that he becomes aware that something is wrong with his breathing on account of the oppression which he feels at his chest, and is alarmed at finding that his roice either leaves him entirely, or is reduced to a mere whisper. In the following case, which has been for some time under my care at the National Hospital for the Paralysed and Epileptic, the chief symptoms of paralysis of the diaphragm, as indicated by Duchenne, will be seen to be fwell-marked; and, although the patient has been conscious of a difficulty of breathing, brought on by the least exertion of an unustial kind, for fifteen months, and unquestionably traceable to defective action of the diaphragm, she is still alive and enjoying on the whole pretty good health.

CASE I. Sarah B., aged 41, married, a tall, thin, bony woman, of pale sallow complexion has always enjoyed good hoalth, and has never been laid up for ary illness. The only member of her family who has saffered from a nervous complaint is her eldest son, aged 14, a remarkedly well-developed boy, who looks more like a strong lad of 20 , and who has been for some time past under my care for epilepsy; which now recurs at very long intervals only. She is of a nervous, excitable temperament, and confesses to be easily moved, and to be subject to depression of spirits, but denies having ever had any hysterical seizures, of any fits of crying and sobbing.

Her present complaint dates from November 1865 . It began very gradually, with a sense of discomfort about the epigastrium (not exactly a pain, bat a sensation of weight) and a difficilty of breathing; she could not fetch her breath, she says, and kept gaping so as to take in more air inside her chest. These sensations came on towards evening, and were most marked when she had had a hard day's work to do, a good deal of washing and ironing to get through. She was living poorly at the time, and, as she had to work hard, she felt herself becoming weaker. The difficulty in breathing was accompanied by a symptom which considerably alarmed her, namely, loss of voice. Frequently, towards evening, she would lose her voice completely, and be compelled to speak in a mere whisper. If she abstained, throughout the day, however, from work requiring a good deal of muscular exertion, and confined herself to mere sewing, for instance, she was free from dyspncod, and could speak in a louder voice. She was always better in the morning; and, if she had gone to bed' voiceless; would wake up after a good night's rest perfectly able to speak. She had no cough at the time, and no pain about the chest to account for the difficulty of breathing; and she felt no soreness; no abnormial sensation in the throat, to which she might refer her occasional and intermittent aphonia.

When I first saw her, the peculiar character of her voice attracted $m y$ attention at once. She spoke like a person who has just been running and is out of breath, and stops between the words to draw in air; with this difference, however, that, instead of her voice improving as she went on talking, it became weaker and weaker, occasionally squeaky, till at last it left her completely, and she could not for a while proceed even in a whisper.

I was struck with the peculiarities of this aphonia, especially as the patient pointed of herself to the epigastrium as the seat of an unpleasant sensation, not to the larynx; while, on examination, no redness of the fauces, no swelling of the torsils, was found to exist.

On exposing her chest, her breathing, when she was perfectly quiet, seemed to be regular and normal, and was not visibly accelerated; but on application of the hand, it was found to be in reality quicker than in health, for the respiratory movements were thirty-two in a minute, and the breathing was acertained to be costal. There was some lateral dilatation of the chest; but the increase in capacity was chiefly obtained by the upward movement of the thoracic parietes: No appreciable change took place in the opigastrium during vary tranquil breathing, 